\title{
IDENTIFICATION OF AMPC B-LACTAMASE-PRODUCING CLINICAL ISOLATES OF ESCHERICHIA COLI
}

\author{
TANUSHREE B GUPTA ${ }^{1 *}$, MALINI SHARIFF ${ }^{1}$, THUKRAL SS ${ }^{1,2}$ \\ ${ }^{1}$ Department of Microbiology, Vallabhbhai Patel Chest Institute, University of Delhi, Vijay Nagar Marg, Delhi, India. \\ ${ }^{2}$ Department of Microbiology \& Immunology, College of Medicine \& Health Sciences, Sultan Qaboos University, Muscat, Oman. \\ Email: tanushree.gupta@agresearch.co.nz
}

Received: 27 July 2017, Revised and Accepted: 18 September 2017

ABSTRACT

Objective: Indiscriminate use of $\beta$-lactam antibiotics has resulted in the emergence of $\beta$-lactamase enzymes. AmpC $\beta$-lactamases, in particular, confer resistance to penicillin, first-, second-, and third-generation cephalosporins as well as monobactams and are responsible for antibiotic resistance in nosocomial pathogens. Therefore, this study was undertaken to screen nosocomial Escherichia coli isolates for the presence and characterization of AmpC $\beta$-lactamases. The study also envisaged on the detection of inducible AmpC $\beta$-lactamases and extended-spectrum $\beta$-lactamases (ESBLs) in AmpC $\beta$-lactamase-producing E. coli.

Methods: A total of 102 clinical isolates of E. coli, were subjected to cefoxitin screening, and screen-positive isolates were further subjected to inhibitorbased detection method, phenotypic confirmatory test, disc antagonism test, polymerase chain reaction (PCR), and isoelectric focusing (IEF).

Results: In this study, $33 \%$ of E. coli were resistant to cefoxitin, of which $35 \%$ were found to be positive for AmpC $\beta$-lactamase by inhibitor-based phenotypic test. Of the AmpC-positive isolates, $83 \%$ were positive for ESBLs, whereas $25 \%$ were producing inducible AmpC $\beta$-lactamases. PCR and IEF showed CIT and EBC types of AmpC $\beta$-lactamases present in the tested isolates.

Conclusion: Our study showed the presence of inducible AmpC enzymes and ESBLs in E. coli isolates and PCR identified more isolates to be AmpC producers.

Key words: AmpC $\beta$-lactamases, Escherichia coli, Extended-spectrum $\beta$-lactamases, Inhibitor (Boronic acid)-based test, Isoelectric focusing.

(C) 2017 The Authors. Published by Innovare Academic Sciences Pvt Ltd. This is an open access article under the CC BY license (http://creativecommons. org/licenses/by/4. 0/) DOI: http://dx.doi.org/10.22159/ajpcr.2017.v10i12.21648

\section{INTRODUCTION}

There has been an implausible rise in the incidence of antibiotic resistance, more importantly to cephalosporins in bacterial pathogens $[1,2]$. Of the various resistance mechanisms, production of $\beta$-lactamases is the most widespread. AmpC $\beta$-lactamases are clinically significant as they confer resistance to a broad spectrum of antibiotics such as penicillin, first-, second-, and third-generation cephalosporins and monobactams such as aztreonam and are not inhibited by commercially available $\beta$-lactamase inhibitors $[3,4]$. Escherichia coli is a commensal and opportunistic pathogen which can be responsible for intestinal as well as urinary tract infections, and hence, is targets for antibiotic therapies [5]. This can lead, in some cases to a high degree of antibiotic resistance. AmpC $\beta$-lactamases are encoded by ampC genes which can be chromosomally or plasmid mediated [6]. In E. coli, ampC is expressed constitutively, but at low level, mutations in the $\mathrm{ampC}$ promoter/attenuator region can result in constitutive overexpression [7]. Plasmid-mediated $a m p C$ genes are also reported in E. coli, which are expressed constitutively in high levels and are also induced by $\beta$-lactams such as ACT-1 $\beta$-lactamases [6]. Hence, plasmid-mediated AmpC $\beta$-lactamases have considerable clinical significance [8]. Moreover, clinical isolates possessing plasmids encoding AmpC enzymes often are resistant to multiple antibiotics hence, leaving few therapeutic options.

Taking into consideration the significance of AmpC $\beta$-lactamases and coexistence of extended-spectrum $\beta$-lactamases (ESBLs) in AmpC $\beta$-lactamase-producing isolates in clinical world, this study was undertaken to identify and characterize different types of AmpC $\beta$-lactamases in E. coli. The present study compared different phenotypic methods with a genotypic method polymerase chain reaction (PCR) to detect AmpC $\beta$-lactamases in clinical isolates of E. coli.

\section{METHODS}

\section{Bacterial isolates}

A total of 102 isolates of E. coli recovered from a variety of clinical specimens were collected from two different hospitals of Delhi during the period from April 2003 to December 2005. All the isolates were identified by standard biochemical methods. E. coli ATCC 25922 was included as a negative control in all the tests described, whereas $E$. coli C600 pMG230 and Klebsiella pneumoniae 48188 were used as positive controls in all the experiments.

\section{Screening for AmpC production}

The isolates were tested for antimicrobial susceptibility to cefoxitin by Kirby-Bauer disc diffusion method [9]. The inhibition zone sizes were interpreted as per the CLSI (formerly NCCLS) guidelines [10]. All the isolates with an inhibition zone diameter of $<18 \mathrm{~mm}$ were selected.

\section{Detection of AmpC $\beta$-lactamases}

The screened positive isolates were tested by an inhibitor (boronic acid)-based detection method to detect AmpC-producing E. coli [11]. Briefly, a stock solution of boronic acid was prepared by dissolving $120 \mathrm{mg}$ of phenylboronic acid (Sigma-Aldrich, St. Louis, USA) in $3 \mathrm{ml}$ dimethyl sulfoxide, to which $3 \mathrm{ml}$ of sterile distilled water was added. Discs were prepared by dispensing $20 \mu \mathrm{l}$ of the stock solution on $30 \mu \mathrm{g}$ of cefotetan discs. These were dried for $30 \mathrm{~min}$ and used immediately or stored in airtight vials with a desiccant at $4^{\circ} \mathrm{C}$. This test was performed by inoculating Mueller-Hinton Agar (MHA) plate with test isolates by the standard disc diffusion method (CLSI/NCCLS) and placing a disc containing $30 \mu \mathrm{g}$ of cefotetan along with a disc containing $30 \mu \mathrm{g}$ of cefotetan and $400 \mu \mathrm{g}$ of boronic acid. The inoculated plates were incubated overnight at $37^{\circ} \mathrm{C}$. Organism showing an increase of $5 \mathrm{~mm}$ of zone diameter around the disc containing cefotetan and boronic acid as 
compared to that of zone diameter around the disc of cefotetan alone was considered as AmpC producer.

\section{Detection of inducible AmpC $\beta$-lactamases}

Disc antagonism test (DAT) was carried out as described by Yan et al., 2002, [12]. Briefly, a disc of cefoxitin $(30 \mu \mathrm{g})$ was kept in the center of the inoculated (test isolate) MHA plate and discs of ceftazidime (CAZ), cefpodoxime, and cefotaxime (CTX) were placed around it in a way that each of these was $15 \mathrm{~mm}$ apart. The plates were incubated overnight at $37^{\circ} \mathrm{C}$. Blunting of the zone of inhibition around any of the cephalosporin discs adjacent to the cefoxitin disc was considered as a positive result.

\section{Phenotypic confirmatory test (PCT) for detection of ESBLs}

This test was performed by the disc diffusion technique as recommended by CLSI (NCCLS). A $\geq 5 \mathrm{~mm}$ increase in the zone diameter for either CAZ or CTX tested in combination with clavulanic acid (CLA), versus its zone when tested alone, confirmed an ESBL-producing organism.

All the media and antibiotic discs used for phenotypic tests were procured from Becton, Dickinson \& Co., USA

\section{DNA extraction}

A few (2-3) colonies of the test isolates were inoculated in $5 \mathrm{ml}$ Luria Bertani broth (Becton, Dickinson \& Co., USA) and incubated overnight at $37^{\circ} \mathrm{C}$. Boiled lysate of each of the cultures was prepared by boiling the culture at $100^{\circ} \mathrm{C}$ for $10 \mathrm{~min}$ and collecting the supernatant after centrifugation at $9838 \times \mathrm{g}$ for $5 \mathrm{~min}$. The supernatant was used as a source of template DNA.

\section{Detection of ampC genes by multiplex PCR}

Detection of plasmid-mediated AmpC $\beta$-lactamase genes ( $a m p C$ ) in all the screened positive isolates was carried out by PCR using the method described by Pérez-Pérez and Hanson 2002, [13]. Family-specific primers, as shown in Table 1, were used to detect different families/ types of AmpC $\beta$-lactamases in the isolates. Each $50 \mu \mathrm{l}$ PCR mixture contained $0.2 \mathrm{mM}$ of each dNTPs (Sigma-Aldrich Chemical Pvt. Ltd, Bengaluru, India), $0.5 \mu \mathrm{M}$ of forward and reverse primers (Sigma-Aldrich Chemical Pvt. Ltd, Bengaluru, India), $1 \mathrm{X}$ reaction buffer (New England Biolabs Inc., USA) with $2 \mathrm{mM}$ of $\mathrm{MgCl}_{2}$ (New England Biolabs Inc., USA), $1.25 \mathrm{U}$ of Taq polymerase (New England Biolabs Inc., USA), and $2 \mu \mathrm{l}$ of DNA. Nuclease-free water was used in all the reactions and as a negative control. PCR was carried out in a PTC- $100^{\mathrm{TM}}$ Programmable thermal cycler (MJ Research Inc.) using the following conditions: $94^{\circ} \mathrm{C}$ for $3 \mathrm{~min}$, $94^{\circ} \mathrm{C}$ for $30 \mathrm{~s}, 64^{\circ} \mathrm{C}$ for $30 \mathrm{~s}$, and $72^{\circ} \mathrm{C}$ for $1 \mathrm{~min}$ for 30 cycles followed by a final extension at $72^{\circ} \mathrm{C}$ for $7 \mathrm{~min}$. PCR products were visualized on a $2 \%$ ultrapure agarose (Sigma-Aldrich, St. Louis, USA) gel stained with ethidium bromide (Sigma-Aldrich, St. Louis, USA, $10 \mathrm{mgL}^{-1}$ ).

\section{Nucleotide sequence analysis of ampC genes}

Nucleotide sequencing of PCR amplicons was undertaken on both strands using respective PCR-specific primers (Table 1) by dideoxychain

Table 1: List of family-specific primers used for amplification of ampC genes

\begin{tabular}{lll}
\hline $\begin{array}{l}\text { Types of AmpC } \\
\text { enzyme }\end{array}$ & Primer & Primer sequence (5-3') \\
\hline MOX-1/2, CMY-1, & MOXMF & GCT GCT CAA GGA GCA CAG GAT \\
CMY-8-11 & MOXMR & CAC ATT GAC ATA GGT GTG GTG C \\
LAT-1 to 4, CMY-2 & CITMF & TGG CCA GAA CTG ACA GGC AAA \\
to 7, BIL-1 & CITMR & TTT CTC CTG AAC GTG GCT GGC \\
DHA-1, DHA-2 & DHAMF & AAC TTT CAC AGG TGT GCT GGG T \\
& DHAMR & CCG TAC GCA TAC TGG CTT TGC \\
ACC & ACCMF & AAC AGC CTC AGC AGC CGG TTA \\
& ACCMR & TTC GCC GCA ATC ATC CCT AGC \\
MIR-1, ACT-1 & EBCMF & TCG GTA AAG CCG ATG TTG CGG \\
& EBCMR & CTT CCA CTG CGG CTG CCA GTT \\
FOX-1 to FOX-5b & FOXMF & AAC ATG GGG TAT CAG GGA GAT G \\
& FOXMR & CAA AGC GCG TAA CCG GAT TGG \\
\hline
\end{tabular}

termination method using the services of the commercial vendor (Link Biotech, India). Sequence analysis and comparisons were performed using nucleotide BLAST, and sequences were compared against the database of $a m p C$ genes present at the NCBI server (http://www.ncbi. nlm.nih.gov).

Detection and characterization of AmpC $\beta$-lactamases by isoelectric focusing (IEF)

Characterization of AmpC $\beta$-lactamases was carried out by IEF, following the procedure of Matthew et al., 1975, [14] with few modifications. Briefly, crude enzyme extract from test isolates was prepared by subjecting the cell pellet from overnight grown cultures to 20 cycles of freezing at $-20^{\circ} \mathrm{C}$ for $30 \mathrm{~min}$ and thawing at $37^{\circ} \mathrm{C}$ for $15 \mathrm{~min}$. Nitrocefin sensitivity test was performed by loading $50 \mu \mathrm{l}$ of nitrocefin solution and $10 \mu \mathrm{l}$ of crude extract of the test organism into a 96-well microtiter plate. The rate of color change was graded on a scale of 5-1. For the score of $5,1 \mu \mathrm{l}$ of crude enzyme extract, and for a score of $1,20 \mu \mathrm{l}$ of crude enzyme extract were loaded on commercially prepared polyacrylamide gels with a $\mathrm{pH}$ range of 3.5-10. Gel electrophoresis was carried out using on a LKB Bromma 2117 Multiphor II electrophoresis unit (Ampholine PAG plate; GE Healthcare Uppsala, Sweden). The gel was run at $1500 \mathrm{~V}, 50 \mathrm{~mA}$, and $30 \mathrm{~W}$ for $90 \mathrm{~min}$. The bands were analyzed by placing a filter paper soaked in nitrocefin and placing it over the gel for $10 \mathrm{~min}$.

\section{RESULTS}

\section{Detection of $\boldsymbol{\beta}$-lactamases in test isolates}

Of the 102 isolates of $E$. coli screened for AmpC $\beta$-lactamases production, 34 were identified as screen positive. Of these screen-positive isolates, 12 were identified as AmpC producers by inhibitor (boronic acid)based test (EC 1, 2, 3, 4, 10, 11, 19, 20, 22, 24, 26, and 29). Of these 12 AmpC producers, 3 isolates, namely, EC 1, 19, and 22 were found positive by DAT suspecting to produce inducible AmpC $\beta$-lactamases and 10 isolates (EC 2, $3,4,10,11,20,22,24,26$, and 29) were found to coproduce ESBLs (Tables 2 and 3).

\section{Detection of $\operatorname{ampC}$ genes}

All the screened positive isolates were subjected to multiplex PCR. Of the 34 screened positive isolates of E. coli, 16 were found to show ampC genes of amplified products of 462 bp (CIT type) and 302 bp (EBC), respectively (Fig. 1). Of these 16 PCR-positive isolates, 13 harbored ampC genes of CIT family (EC 2, 3, 4, 10, 11, 14, 15, 20, 24, 26, 29, 32, and 34 ) and 3 (EC 1, 19, and 22) of EBC family (Table 4). None of the tested isolates harbored genes for MOX, ACC, DHA, and FOX families. CIT-type $a m p C$ gene was found to be predominant in the PCR-positive isolates (Table 4). Nucleotide sequencing of the CIT family amplicons was found to have $100 \%$ homology to CMY-2 and EBC family amplicons to have $100 \%$ homology to ACT-1-type AmpC $\beta$-lactamases. PCR detected four additional isolates: EC $14,15,32$, and 34 to produce AmpC $\beta$-lactamases as compared to phenotypic test, and all these isolates produced CITtype AmpC enzyme (Table 3).

\section{Characterization of AmpC $\boldsymbol{\beta}$-lactamases by IEF}

All the screened positive isolates were subjected to IEF. Of the 34 screened positive $E$. coli, bands of $\mathrm{pI}$ values of $>8.4$ corresponding to CIT or MOX types were detected in 6 isolates (EC 2, 24, 26, 30, 31, and

Table 2: Number of $E$. coli isolates positive for $\beta$-lactamases by various phenotypic methods

\begin{tabular}{ll}
\hline Detection methods & $\begin{array}{l}\text { Number of isolates } \\
\text { positive (\%) }\end{array}$ \\
\hline Cefoxitin screening $\mathrm{n}=102$ & $34(33)$ \\
Inhibitor (boronic acid)-based detection $\mathrm{n}=34$ & $12(35)$ \\
DAT $\mathrm{n}=12$ & $3(25)$ \\
PCT (PAT) $n=12$ & $10(83)$ \\
\hline
\end{tabular}

$\mathrm{n}$ : Total number of isolates tested, PCT: Phenotypic confirmatory test, DAT: Disc antagonism test, E. coli: Escherichia coli 
Table 3: Representation of different clinical isolates of $E$. coli found positive by different detection method

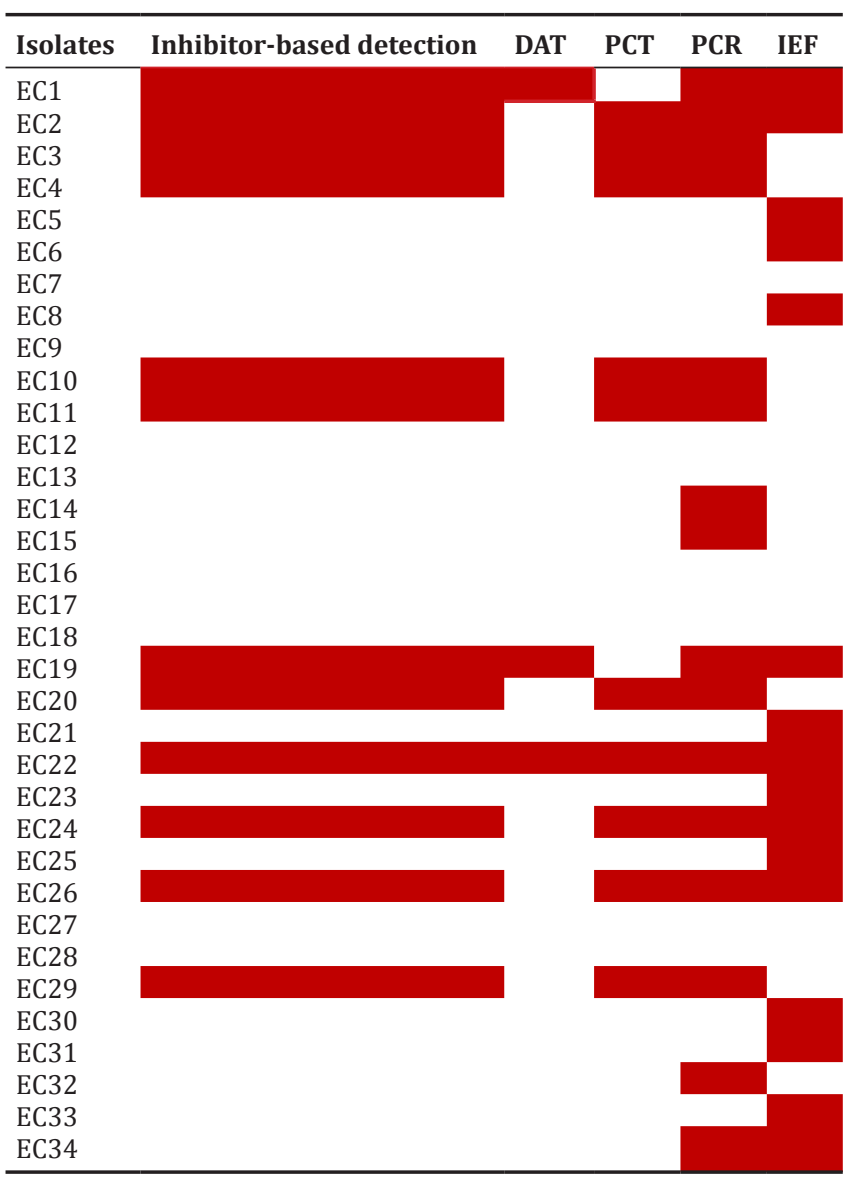

Red highlight depicts isolates positive for $\beta$-lactamases by respective methodologies, PCR: Polymerase chain reaction, PCT: Phenotypic confirmatory test, IEF: Isoelectric focusing, DAT: Disc antagonism test, E. coli: Escherichia coli

Table 4: Detection and characterization of AmpC $\beta$-lactamases by PCR

\begin{tabular}{ll}
\hline AmpC $\boldsymbol{\beta}$-lactamase families & Number of isolates positive (\%) \\
\hline CIT & $13(81.25)$ \\
EBC & $3(18.75)$ \\
MOX & - \\
DHA & - \\
ACC & - \\
FOX & - \\
Total & 16 \\
\hline
\end{tabular}

Total number of isolates tested $=34$, PCR: Polymerase chain reaction

34) and bands of pI 8.4 corresponding to EBC type in 3 (EC 1, 19, and 22). Bands of pI values ranging between 6.3 and 7.2 corresponding to either FOX or DHA types in 3 (EC 5, 6, and 21) and bands of pI 7.6 corresponding to ACC type were detected in 4 isolates (EC 8, 23, 25, and 33) (Fig. 2 and Tables 3 and 5). Interestingly, in 12/34 isolates of E. coli, bands of pI 5.4 could be detected, which did not correspond to any of the known AmpC types (data not shown). In addition, 6 of the isolates showed the presence of multiple $\beta$-lactamase bands (data not shown).

\section{DISCUSSION}

Indiscriminate and large-scale use of $\beta$-lactam antibiotics has led to the emergence of $\beta$-lactamase enzymes such as ESBLs and AmpC $\beta$ - lactamases in a variety of bacterial pathogens and are responsible for high-level resistance to these antibiotics [15-20]. Varying rates of incidence ranging from as low as $1.6 \%$ to as high as $60 \%$ of AmpC-
Table 5: Detection and characterization of AmpC $\beta$-lactamases by IEF

\begin{tabular}{lll}
\hline $\begin{array}{l}\text { pI values of } \\
\text { bands detected }\end{array}$ & $\begin{array}{l}\text { Corresponding } \\
\text { presumptive AmpC types }\end{array}$ & $\begin{array}{l}\text { Number of isolates } \\
\text { positive (\%) }\end{array}$ \\
\hline$>8.4$ & CIT, MOX & $6(17.6)$ \\
8.4 & EBC & $3(8)$ \\
7.6 & ACC & $4(11)$ \\
$6.3-7.2$ & FOX, DHA & $3(8)$ \\
5.4 & - & $12(35.2)$ \\
\hline
\end{tabular}

Total number of isolates tested $=34$, IEF: Isoelectric focusing

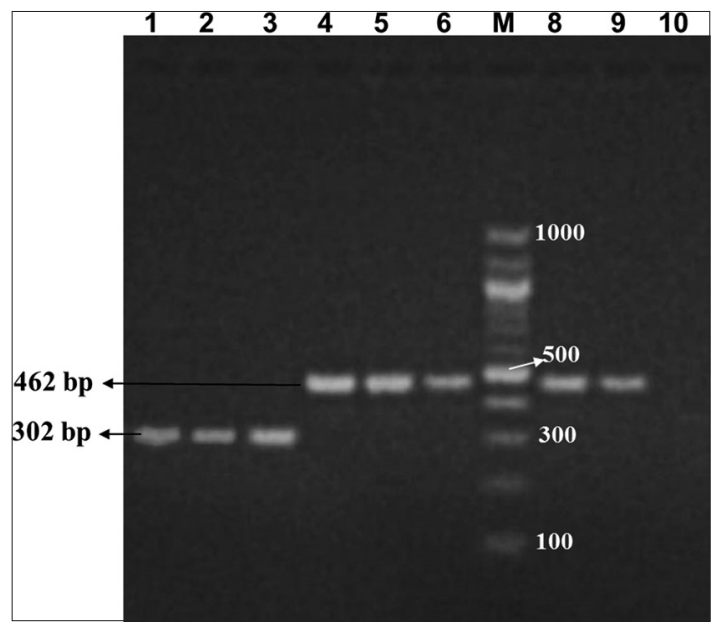

Fig. 1: Identification of AmpC $\beta$-lactamase types by polymerase chain reaction; Lanes 1: Positive control for EBC type: 2 and 3: Positive isolates of Escherichia coli for EBC type; 4-9: Positive isolates of $E$. coli for CIT type, M: 100 bp molecular weight marker; 10: Water control as negative

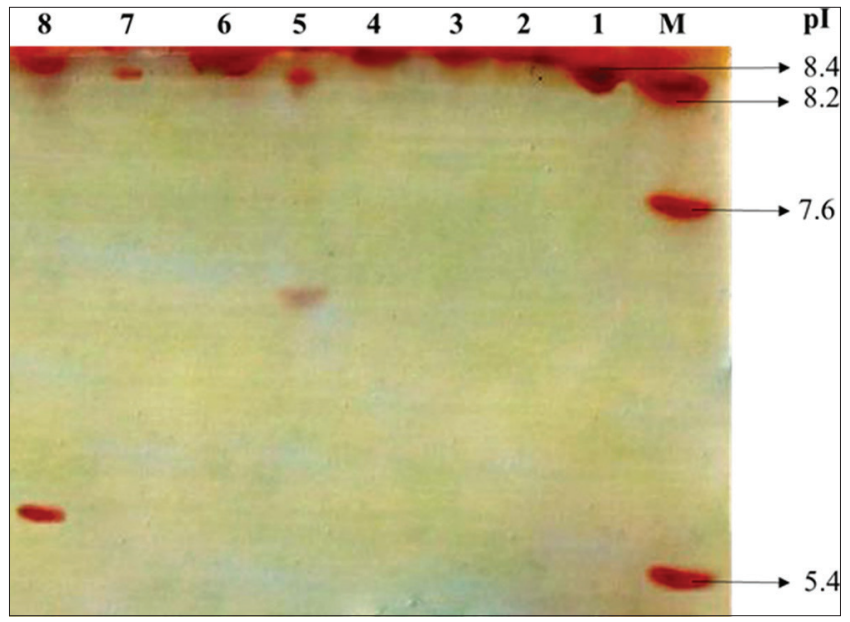

Fig. 2: Example of isoelectric focusing gel electrophoresis carried out in this study. Lanes M: Standard marker of different pI values; 1: Positive control for EBC type; 2, 3, 4, 6, and 8: Isolates positive for CIT/MOX types; lane 8 shows the presence of another band of a different pI value; 5 and 7: Isolates positive for EBC types, lane 5 also shows the presence of a band of different pI value

producing E. coli isolates have been reported from various parts of the world [11,21-24]. Studies from different geographical areas in India have reported 6\% to $41 \%$ of $E$. coli isolates to be AmpC producers [22,25-28]. Our study showed similar results (35\% by phenotypic test) to some of the researchers reporting a high incidence of AmpC $\beta$-lactamases in E. coli, indicating a rising trend of resistance, which should be a cause of concern. 
Amoxicillin-CLA combination is usually given in treating infection caused by $\beta$-lactamase-producing isolates because CLA is known to be an active inhibitor of ESBLs. Since CLA can act as an inducer for AmpC $\beta$-lactamases, it becomes imperative to check for the presence of inducible AmpC $\beta$-lactamases in the clinical isolates. Studies have reported the presence of inducible AmpC $\beta$-lactamases in $4-21 \%$ of E. coli isolates $[25,29]$. Our study showed similar results with $16.6 \%$ of the AmpC-positive isolates to be inducible; however, more number of isolates need to be tested to show an increasing trend. Hence, testing for the presence of inducible AmpC producers becomes important, as there can be a therapeutic failure if antibiotics inducing the enzymes are administered for treating the infection empirically.

A multiplex PCR which distinguished plasmid-mediated AmpC enzymes from chromosomally mediated and also differentiated between six different families of plasmid-mediated AmpC $\beta$-lactamases was used in this study. A number of workers have used PCR to detect the presence of $a m p C$ genes $E$. coli and have reported PCR to be more sensitive than phenotypic methods to detect AmpC-producing isolates [4,30-32]. Our study showed the presence of $a m p C$ gene for plasmid-mediated AmpC enzymes in $47 \%$ of the screen-positive isolates of $E$. coli and was found to detect four additional AmpC producers than inhibitor-based method. In the present study, a high percentage (81.2\%) of the PCR-positive isolates of $E$. coli were shown to produce CIT type of AmpC $\beta$-lactamases, followed by $18.75 \%$ producing EBC type. Our study corroborates the findings of other studies, showing a high percentage $(88 \%)$ of $E$. coli isolates to produce CIT type of AmpC enzymes [28,33,34]. However, there are studies which reported a lower prevalence, $11 \%, 34 \%$, and $56 \%$, respectively, of the E. coli isolates to be producing CIT-type AmpC $\beta$-lactamases $[4,35,36]$. The presence of EBC family or ACT-1 subtype of AmpC enzymes in $E$. coli has been reported in many studies; however, EBC-type AmpC $\beta$-lactamases was found to be more prevalent in Klebsiella spp. [37-40]. In the present study, we found $\sim 19 \%$ of the inducible AmpC-producing E. coli isolates to be of EBC (ACT-1) type. In our study, inducible AmpC $\beta$-lactamases were detected by DAT, IEF as well as PCR.

The inhibitor-based phenotypic test detected less number of isolates to be AmpC positive as compared to the PCR, and this suggests that PCR should be used as the gold standard method for identification of beta-lactamases. However, more number of isolates need to be tested to confirm this.

Detection and characterization of $\beta$-lactamases employing IEF were for the first time carried out by Matthew et al. in 1975 [14]. Subsequently, IEF was used for characterizing AmpC $\beta$-lactamases in a number of bacterial pathogens $[12,41-43]$. In the present study, $\beta$-lactamase bands of pI values $>8.4$, corresponding to CIT type, bands of pI value 8.4 corresponding to EBC type, bands of $\mathrm{pI}$ values ranging between 6.3-7.2 corresponding to FOX/DHA, and bands of pI value 7.6 corresponding to ACC type AmpC enzymes were observed. These were further confirmed by PCR to be the respective AmpC enzymes except ACC and FOX or DHA types. According to our PCR results, none of the E. coli isolates harbored ampC genes for ACC and DHA families. In comparison to PCR, IEF detected less isolates to produce CIT type but extraisolates to produce ACC and FOX-/DHA-type AmpC $\beta$-lactamases. Moreover, bands of pI value 5.4 were detected which did not correspond to any of the known AmpC $\beta$-lactamases. This suggests that there may be a possibility that these $\mathrm{pI}$ bands correspond to some ESBLs and that some of the tested isolates coproduced ESBLs. It was found that $83 \%$ of the AmpCproducing isolates in this study were also producing ESBLs. Many studies have shown the presence of ESBLs along with AmpC enzymes which also showed bands of different pI values [24,27,44-47]. In this study, there was one isolate, EC 22, which was found to be positive for inducible AmpC $\beta$-lactamases, coproduced ESBL and was found to harbor genes for ACT-1 subtype of AmpC $\beta$-lactamase. This coexistence of multiple enzymes in clinical isolates may restrict the therapeutic options available for treating cases infected with such pathogens.

\section{CONCLUSION}

Our findings may suggest that there is a need to initiate steps to rationalize the use of the $\beta$-lactams and also to have a more vigorous surveillance for detection of such resistance in clinical isolates both at the hospital as well as at the community level. However, a larger set of E. coli isolates along with other nosocomial pathogens need to be tested to have more substantiate data. This constitutes the part of our future studies.

\section{ACKNOWLEDGMENT}

This research was funded by the Indian Council of Medical Research, New Delhi.

We would like to thank Dr. George A Jacoby (Lahey Clinic, USA) for providing the AmpC-positive control for this study.

\section{REFERENCES}

1. Jones RN. Resistance patterns among nosocomial pathogens: Trends over the past few years. Chest 2001;119 2 Suppl:397S-404.

2. Egervärn M, Englund S, Ljunge M, Wiberg C, Finn M, Lindblad M, et al. Unexpected common occurrence of transferable extended spectrum cephalosporinase-producing Escherichia coli in Swedish surface waters used for drinking water supply. Sci Total Environ 2017;587-588:466-72.

3. Philippon A, Arlet G, Jacoby GA. Plasmid-determined AmpC-type beta-lactamases. Antimicrob Agents Chemother 2002;46(1):1-11.

4. Tan TY, Ng LS, He J, Koh TH, Hsu LY. Evaluation of screening methods to detect plasmid-mediated AmpC in Escherichia coli, Klebsiella pneumoniae, and Proteus mirabilis. Antimicrob Agents Chemother 2009;53(1):146-9.

5. Pitout JD. Extraintestinal pathogenic Escherichia coli: A combination of virulence with antibiotic resistance. Front Microbiol 2012;3:9.

6. Jacoby GA. AmpC beta-lactamases. Clin Microbiol Rev 2009;22(1):161-82.

7. Tracz DM, Boyd DA, Bryden L, Hizon R, Giercke S, Van Caeseele $\mathrm{P}$, et al. Increase in ampC promoter strength due to mutations and deletion of the attenuator in a clinical isolate of cefoxitin-resistant Escherichia coli as determined by RT-PCR. J Antimicrob Chemother 2005;55(5):768-72.

8. Munier GK, Johnson CL, Snyder JW, Moland ES, Hanson ND, Thomson KS. Positive extended-spectrum-beta-lactamase (ESBL) screening results may be due to $\mathrm{AmpC}$ beta-lactamases more often than to ESBLs. J Clin Microbiol 2010;48(2):673-4.

9. Bauer AW, Kirby WM, Sherris JC, Turck M. Antibiotic susceptibility testing by a standardized single disk method. Am J Clin Pathol 1966;45(4):493-6.

10. Clinical and Laboratory Standards Institute. Performance Standards for Antimicrobial Susceptibility Testing. Wayne, PA: Clinical and Laboratory Standards Institute; 2007. p. 17.

11. Coudron PE. Inhibitor-based methods for detection of plasmidmediated AmpC beta-lactamases in Klebsiella spp. Escherichia coli, and Proteus mirabilis. J Clin Microbiol 2005;43(8):4163-7.

12. Yan JJ, Ko WC, Jung YC, Chuang CL, Wu JJ. Emergence of Klebsiella pneumoniae isolates producing inducible DHA-1 beta-lactamase in a university hospital in Taiwan. J Clin Microbiol 2002;40(9):3121-6.

13. Pérez-Pérez FJ, Hanson ND. Detection of plasmid-mediated AmpC beta-lactamase genes in clinical isolates by using multiplex PCR. J Clin Microbiol 2002;40(6):2153-62.

14. Mathew A, Harris AM, Marshall MJ, Ross GW. The use of analytical isoelectric focusing for detection and identification of beta-lactamases. J Gen Microbiol 1975;88(1):169-78.

15. Pascual V, Alonso N, Simó M, Ortiz G. Bloodstream infections caused by Escherichia coli producing AmpC ß-lactamases: Epidemiology and clinical features. Eur J Clin Microbiol Infect Dis 2016;35(12):1997-2003.

16. Manyahi J, Moyo SJ, Tellevik MG, Ndugulile F. Detection of CTX-M-15 beta-lactamases in Enterobacteriaceae causing hospitaland community-acquired urinary tract infections as early as 2004, in Dar es Salaam, Tanzania. BMC Infect Dis 2017;17(1):282.

17. Ahn JY, Ann HW, Jeon Y. The impact of production of extendedspectrum B-lactamases on the 28-day mortality rate of patients with Proteus mirabilis bacteremia in Korea. BMC Infect Dis 2017;17(1):327.

18. Akinyemi KO, Iwalokun BA, Oyefolu AO, Fakorede CO. Occurrence of extended-spectrum and AmpC ß-lactamases in multiple drug resistant Salmonella isolates from clinical samples in Lagos, Nigeria. 
Infect Drug Resist 2017;10:19-25.

19. Sandhiya R, Lakshmi PR, Esthermary S. Antibiotic susceptibility pattern and ESBL prevalence in Escherichia coli isolates from pus samples in a tertiary care hospital. Int J Pharm Pharm Sci 2015;7(3):263-4.

20. Jain S, Walia G, Malhotra R. Prevalence and antimicrobial susceptibility pattern of ESBL producing gram negative bacilli in 200 cases of urinary tract infections. Int J Pharm Pharm Sci 2014;6(10):210-1.

21. da Silva Dias RC, Borges-Neto AA, D'Almeida Ferraiuoli GI, deOliveira MP, Riley LW, Moreira BM. Prevalence of AmpC and other beta-lactamases in enterobacteria at a large urban university hospital in Brazil. Diagn Microbiol Infect Dis 2008;60:79-87.

22. Singh SK, Seema K, Gupta M. Detection of AmpC $\beta$-lactamase and adherence factors in uropathogenic Escherichia coli isolated from aged patients. Microb Pathog 2016;100:293-8.

23. Salamat S, Ejaz H, Zafar A, Javed H. Detection of AmpC ß-lactamase producing bacteria isolated in neonatal sepsis. Pak J Med Sci 2016;32(6):1512-6.

24. Kahraman BB, Siğirci BD, Celik B. Detection of extended-spectrum $\beta$-lactamase and AmpC $\beta$-lactamase producing Escherichia coli isolates from chickens. Vet Fakülte Derg 2016;22(4):591-6.

25. Arora $\mathrm{S}, \mathrm{Bal} \mathrm{M}$. AmpC beta-lactamase producing bacterial isolates from Kolkata hospital. Indian J Med Res 2005;122(3):224-33.

26. Singhal S, Mathur T, Khan S, Upadhyay DJ, Chugh S, Gaind R, et al. Evaluation of methods for AmpC beta-lactamase in gram negative clinical isolates from tertiary care hospitals. Indian J Med Microbiol 2005;23(2):120-4

27. Singh RM, Pal NK, Sarkar S, Gupta MS. Surveillance on extended spectrum [beta]-lactamase and AmpC [beta]-lactamase producing gram negative isolates from nosocomial infections. Arch Clin Microbiol 2012;3(3):1-7.

28. Chakraborty A, Adhikari P, Shenoy S, Saralaya V. Characterization of plasmid mediated AmpC producing Escherichia coli clinical isolates from a tertiary care hospital in South India. Indian J Pathol Microbiol 2014;57(2):255-8

29. Kaur DC, Puri JS, Kulkarni SS, Jayawant A. Prevalence of AmpC B-lactamases in clinical isolates of E. coli from a tertiary care rural hospital. Int J Pharm Pharm Sci 2015;7(6):165-8.

30. Ding H, Yang Y, Lu Q, Wang Y, Chen Y, Deng L, et al. The prevalence of plasmid-mediated AmpC $\beta$-lactamases among clinical isolates of Escherichia coli and Klebsiella pneumoniae from five children's hospitals in China. Eur J Clin Microbiol Infect Dis 2008;27(10):915-21.

31. Peter-Getzlaff S, Polsfuss S, Poledica M, Hombach M, Giger J, Böttger EC, et al. Detection of AmpC beta-lactamase in Escherichia coli: Comparison of three phenotypic confirmation assays and genetic analysis. J Clin Microbiol 2011:49(8):2924-32.

32. Ingti B, Paul D, Maurya AP, Bora D, Chanda DD, Chakravarty A, et al. Occurrence of bla DHA-1 mediated cephalosporin resistance in Escherichia coli and their transcriptional response against cephalosporin stress: A report from India. Ann Clin Microbiol Antimicrob 2017;16(1):1-8.

33. Woodford N, Reddy S, Fagan EJ, Hill RL, Hopkins KL, Kaufmann ME, et al. Wide geographic spread of diverse acquired AmpC $\beta$-lactamases among Escherichia coli and Klebsiella spp. in the UK and Ireland. J Antimicrob Chemother 2007;59(1):102-5.
34. Barua T, Shariff M, Thukral SS. Detection and characterization of AmpC B-Lactamases in Indian clinical isolates of Escherichia coli, Klebsiella pneumoniae and Klebsiella oxytoca. Univers J Microbiol Res 2013;1(2):15-21.

35. Mulvey MR, Bryce E, Boyd DA, Ofner-Agostini M, Land AM, Simor AE, et al. Molecular characterization of cefoxitin-resistant Escherichia coli from Canadian hospitals. Antimicrob Agents Chemother 2005;49(1):358-65

36. Pitout JD, Gregson DB, Church DL, Laupland KB. Population-based laboratory surveillance for AmpC $\beta$-lactamase producing Escherichia coli, Calgary. Emerg Infect Dis 2007;13(3):443-8.

37. Alvarez M, Tran JH, Chow N, Jacoby GA. Epidemiology of conjugative plasmid-mediated AmpC $\beta$-lactamases in the United States. Antimicrob Agents Chemother 2004;48(2):533-7.

38. Tenover FC, Emery SL, Spiegel CA, Bradford PA, Eells S, Endimiani A, et al. Identification of plasmid-mediated AmpC $\beta$-lactamases in Escherichia coli, Klebsiella spp., and Proteus species can potentially improve reporting of cephalosporin susceptibility testing results. J Clin Microbiol 2009;47(2):294-9.

39. Hussain M, Hasan F, Shah AA, Hameed A, Jung M, Rayamajhi N, et al. Prevalence of class A and AmpC b-lactamases in clinical Escherichia coli isolates from Pakistan Institute of Medical Science, Islamabad, Pakistan. Jpn J Infect Dis 2011;64(3):249-52.

40. Basavaraju A, Muttaraju P. Detection of plasmid-mediated Ampc $\beta$-lactamases among E. coli and Klebsiella pneumoniae by multiplex PCR. Ann Pathol Lab Med 2016;3(3):230-6.

41. Navarro F, Perez-Trallero E, Marimon JM, Aliaga R, Gomariz M, Mirelis B. CMY-2-producing Salmonella enterica, Klebsiella pneumoniae, Klebsiella oxytoca, Proteus mirabilis and Escherichia coli strains isolated in Spain (October 1999-December 2000). J Antimicrob Chemother 2001;48(3):383-9.

42. Miró E, Mirelis B, Navarro F, Matas L, Giménez M, Rabaza C. Escherichia coli producing an ACC-1 class C $\beta$-lactamase isolated in Barcelona, Spain. Antimicrob Agents Chemother 2005;49(2):866-7.

43. Li Y, Li Q, Du Y, Jiang X, Tang J, Wang J, et al. Prevalence of plasmidmediated AmpC $\beta$-lactamases in a Chinese university hospital from 2003 to 2005: First report of CMY-2-type AmpC $\beta$-lactamase resistance in China. J Clin Microbiol 2008;46(4):1317-21.

44. Pai H, Kang CI, Byeon JH, Lee KD, Park WB, Kim HB, et al. Epidemiology and clinical features of bloodstream infections caused by AmpC-type- $\beta$-lactamase-producing Klebsiella pneumoniae. Antimicrob Agents Chemother 2004:48(10):3720-8

45. Sinha P, Sharma R, Rishi S, Sharma R, Sood S, Pathak D. Prevalence of extended spectrum beta lactamase and $\mathrm{AmpC}$ beta lactamase producers among Escherichia coli isolates in a tertiary care hospital in Jaipur. Indian J Pathol Microbiol 2008;51(3):367-9.

46. Karkaba A, Grinberg A, Benschop J, Pleydell E. Characterisation of extended spectrum $\beta$-lactamase and AmpC $\beta$-lactamase-producing Enterobacteriaceae isolated from companion animals in New Zealand. N Z Vet J 2016;65(2):105-12.

47. Yaici L, Haenni M, Métayer V, Saras E, Zekar FM, Ayad M, et al. Spread of ESBL/AmpC-producing Escherichia coli and Klebsiella pneumoniae in the community through ready-to-eat sandwiches in Algeria. Int J Food Microbiol 2017;245:66-72. 